\title{
Movimentos da crosta e relações entre Tectônica e dinâmica atmosferica
}

Crustal movements and Relationship between Tectonics and atmospheric dYNAmics

Jackeline Montelro Faustinoni ${ }^{1}$, Celso Dal Ré Carneiro²

1-Graduanda em Geologia, Instituto de Geociências, Universidade Estadual de Campinas, Campinas, SP. e-mail: faustinoni@gmail.com 2-Instituto de Geociências, Universidade Estadual de Campinas, Campinas, SP.

\section{Manuscrito:}

Recebido: 14/07/2014

Corrigido: 06/07/2015

Aceito: 21/07/2015

Citation: Faustinoni J.M., Carneiro C.D.R. Movimentos da crosta e relações entre Tectônica e dinâmica atmosférica. Terræ Didatica, 11(3):173-181. < http://www. ige.unicamp.br/terraedidatica/>.

Keywords: Geology, atmospheric circulation, oceans, orogenesis, teachinglearning.
ABSTRACT: On a global scale, large uplifted areas play a fundamental role in the dynamics of fluid spheres of Earth. The rising air cools in mountainous areas and the moisture condenses, causing orographic rainfall and generating aridity in shadow zones. Long mountain ranges also increase the tortuosity of tropospheric winds, participate in the control of the planetary albedo and influence the global energy balance. This literature review focuses on effects on atmospheric circulation caused by large-scale relief features and borders of land masses (continents). Endogenous processes interfere with weathering and erosion and, therefore, in land and water cycles of chemical elements such as carbon and nitrogen. Consensus does not exist in the understanding of such dynamics: many researchers attribute to Plate Tectonics a decisive role in global climate change over geological time, while others identify just a simple but intriguing connection. The article presents a proposal for a didactic activity for visualizing interactions between land surface and atmosphere.

\section{Introdução}

Compensações isostáticas da crosta terrestre controlam tanto os processos de soerguimento associados à elevação de cadeias de montanhas (denominada atividade orogênica ou orogênese), quanto a subsidência e geração de depressões e bacias sedimentares pela atuação de falhas (tafrogênese). Raramente tais conceitos são abordados em textos de divulgação científica, embora sejam indispensáveis para a compreensão adequada da correlação entre movimentos da crosta e dinâmica atmosférica.

A isostasia é, essencialmente, o equilíbrio vertical da crosta terrestre (litosfera) sobre o substrato mantélico, controlado pela diferença de densidade das rochas que compõem a crosta e o manto. $\mathrm{O}$ relevo (topografia) resultante das diferenças de densidade na crosta é variável devido a mudanças de espessura dos pacotes litosféricos: o acúmulo de material gera sobrepeso e, consequentemente, ocorre afundamento da região (subsidência), enquanto o alívio de peso pode induzir emergência do terreno (soerguimento).

Tanto a criação de cadeias montanhosas (orogênese) quanto a formação de bacias (tafrogênese) são respostas a movimentos de placas tectônicas e/ou deformações que ocorrem no interior das placas. A depender da característica predominante do regime tectônico (compressão ou distensão) tem-se, respectivamente, o soerguimento ou a subsidência do terreno.

A presente síntese bibliográfica relaciona as alterações topográficas regionais causadas por esses processos e sintetiza sua interferência direta nos padrões de circulação atmosférica e oceânica. Os efeitos globais das criação de novas feições de relevo de dimensões continentais e da alteração de limites das terras emersas incluem a modificação dos processos de denudação (intemperismo e erosão) em escala global bem como mudanças nos ciclos do carbono e de outros elementos químicos. 


\section{Objetivos e métodos}

Este artigo tem três objetivos principais: (a) sintetizar conhecimentos fundamentais do campo teórico da Tectônica vinculados à origem de grandes cadeias de montanhas e relacioná-los com a dinâmica externa do planeta e padrões climáticos mundiais; (b) reunir bibliografia especializada e de apoio sobre os seguintes tópicos: ciclos orogenéticos, causas da orogênese, Tectônica de Placas e dinâmica externa do planeta; padrões climáticos globais; influência de eventos tectônicos de soerguimento, isostáticos ou orogênicos, na dinâmica atmosférica ou vice-versa; (c) idealizar e sugerir atividade prática para ser aplicada em sala de aula com a finalidade de ajudar o estudante a visualizar as interferências das alterações crustais sobre a dinâmica atmosférica ou vice-versa.

Ao longo da pesquisa, foi realizada síntese dos assuntos relativos ao objeto de investigação, envolvendo contínua identificação de material bibliográfico de interesse e fichamento sistemático. $\mathrm{O}$ fichamento dos textos que embasam a pesquisa foi extremamente útil para confrontar modelos e ideias ainda não consolidados acerca dos padrões gerais de circulação das esferas fluidas da Terra, deriva continental, Tectônica de Placas e, principalmente, suas inter-relações. Algumas referências bibliográficas listadas inicialmente não ofereceram contribuição direta para a pesquisa, mas ajudaram a formar visão panorâmica dos textos que se ocupam estritamente do tema proposto. Por este motivo, a literatura foi dividida de acordo com uma classificação de bibliografia de referência (específica) e de apoio.

O fichamento da bibliografia de referência contribuiu sobretudo para o desenvolvimento da atividade prática, na medida em que permitiu avaliar os principais conceitos envolvidos e identificar tanto algumas questões elementares, como os principais paradoxos e dificuldades que podem emergir na aprendizagem do tema pesquisado. Junto a isso, foram pesquisados modelos de atividades lúdico-práticas e outras técnicas didáticas utilizadas na difusão do conhecimento geológico no ensino básico.

\section{Principais visões sobre o tema}

Os processos tectônicos modificam a morfologia e a composição da superfície terrestre, interferindo física e quimicamente na atmosfera. Em termos físicos, a dinâmica das placas participa decisivamente na formação de grandes cadeias de montanhas que, por sua vez, determinam a distribuição das precipitações orográficas. Em áreas ativas da crosta, as transformações de longo prazo são também influenciadas pelo tectonismo local. Desse modo, graças à acentuação de desníveis topográficos, aparecem inúmeros registros da influência da tectônica na evolução do relevo. São processos que ocorrem em escalas temporais mais curtas do que os grandes ciclos acima referidos, porém constituem, igualmente, fatores importantes de redirecionamento das massas de ar.

Do ponto de vista dos fenômenos químicos, é bem conhecida a interferência da Tectônica no ciclo do carbono - com seus feedbacks positivos e negativos - que determinam variações das quantidades de carbono atmosférico na Terra, tanto pela adição quanto pela remoção de $\mathrm{CO}_{2}$, graças aos processos de metamorfismo, vulcanismo ou intemperismo de rochas silicáticas (Ruddiman 1997).

A construção e destruição da crosta terrestre é determinada por processos tectônicos que promovematividade sísmica, vulcânica, metamórfica, orogenética e movimentos isostáticos. Devido à abrangência do tema, optamos por caracterizar especificamente os processos de soerguimento/ subsidência (isostáticos e orogênicos) para ao final sintetizar o conhecimento e, em seguida, estudar a relação entre tectônica e dinâmica climática.

A movimentação tectônica é fenômeno global que envolve ciclos de aglutinação e fissão de supercontinentes (Hasui 2012a, 2012b). Mudanças lentas, porém radicais, modificam a disposição da crosta e reconfiguram a distribuição de massas continentais e oceânicas. $\mathrm{O}$ registro deixado pelas alterações é cada vez mais escasso, quanto mais nos aprofundamos no passado geológico; por esse motivo as evidências mais abundantes datam da era Cenozoica (65,5 Ma ao Recente, ver Gradstein et al. 2004).

\section{Fundamentação Teórica}

Vivenciamos um intervalo interglacial, no Holoceno, em que coexistem grandes capas de gelo na Antártida e na Groenlândia e no cume de algumas áreas montanhosas; tais condições são típicas apenas para breves intervalos (da ordem de apenas 10\%) dos últimos milhões de anos. Assim, o clima do Holoceno não é o mais adequado para ser tomado como referência do clima terrestre (Hay et al. 1997). 
Segundo Hay et al. (2002), Molnar et al. (1990) e Ruddiman (1997), a compreensão do conceito de soerguimento é imprescindível para desenvolvimento dos estudos acerca da interação entre Tectônica de Placas e Clima. É necessário diferenciar nas áreas de estudo se o soerguimento foi real ou aparente, ou melhor, orogênico ou isostático, para avaliar se o fator determinante da reconfiguração da dinâmica terrestre foi a Tectônica ou a mudança climática.

A isostasia é, essencialmente, o equilíbrio vertical da crosta terrestre (litosfera) sobre o substrato mantélico, controlado pela diferença de densidade dos dois componentes. O modelo explicativo da isostasia consiste na integração dos modelos de Airy e Pratt (Watts 2001). A alteração topográfica resultante das diferenças de densidade é variável devido a mudanças da espessura dos pacotes litosféricos: o acúmulo de material gera sobrepeso e, consequentemente, ocorre afundamento da região (subsidência), ao passo que o alívio de peso provoca a elevação do terreno.

O soerguimento orogênico - entenda-se a criação de cadeias montanhosas (elevação da crosta) por movimentos tectônicos - ocorre, mais comumente, nos limites de placas convergentes (áreas de colisão e subdução). Em oposição ao soerguimento existe o movimento de subsidência da crosta - rebaixamento da superfície terrestre comum em eventos tectônicos de distensão regional, falhamento e formação de grandes bacias e rift-valleys. A alteração topográfica ocasionada pelos fenômenos acima gera efeitos macroclimáticos, ou seja, de grande amplitude, que modificam os padrões regionais de circulação atmosférica. Em grande escala, quando a mudança topográfica é subaquática, como nas cadeias oceânicas, as novas barreiras assim criadas alteram os padrões de circulação das correntes oceânicas profundas em escala mundial. Em escala menos abrangente, variações microclimáticas promovem o resfriamento regional de áreas soerguidas, como, por exemplo, depois da elevação de uma dada superfície a níveis mais frios da atmosfera, ou na criação de zonas de alta e baixa pressão (Liccardo 2010).

Feições topográficas de grande magnitude, como platôs e montanhas, por funcionarem como obstáculos, geram irregularidades na circulação atmosférica, resultando no aumento da força dos ventos, bloqueio de fluxos zonais, intensificação dos meandros das correntes de jato (Ruddiman 1997). Dentre todos os efeitos diretos causados na atmosfera pelo soerguimento de montanhas o mais perceptível é o fenômeno das chuvas orográficas, em que se intensifica a quantidade de precipitação a barlavento da montanha, enquanto que a sotavento forma-se uma área seca denominada zona de sombra.

Superfícies que foram soerguidas atingem níveis mais altos da atmosfera e são, obviamente, mais frias; sob essas condições há maior preservação de áreas cobertas por neve, interferindo também no albedo planetário e no balanço energético (Molnar et al. 1990).

Mudanças climáticas podem ser fruto de alterações da composição atmosférica. A Tectônica de Placas pode influenciar esse parâmetro na medida em que as taxas de $\mathrm{CO}_{2}$ são controladas, dentre outros fatores, pelo metamorfismo e magmatismo, ambos fortemente relacionados a ambientes geotectônicos ativos (zonas de subdução e dorsais oceânicas). Nos processos metamórficos, o dióxido de carbono, oriundo da subdução de carbonatos, é liberado na atmosfera por meio de exalação por vulcanismo. Já sua remoção ocorre quando do soterramento de carvão orgânico ou por intemperismo de rochas silicáticas para a formação de carbonatos (Toniolo \& Carneiro 2010, Raymo et al. 1988, apud Hay et al. 2002 p.752). A remoção ou liberação do gás na atmosfera não determina se haverá resfriamento ou aquecimento global, considerando-se que o que é de fato relevante para a definição de um ou outro acontecimento é o balanço entre feedbacks positivos e negativos (Berner \& Berner 1997, apud Hay et.al. 2002).

\section{Desafios e contradições}

A partir das evidências, dados e estudos sobre a contemporaneidade do possível surgimento de cadeias de montanhas recentes e os fenômenos de glaciação que ocorreram durante o Cenozoico (van Anden 1994) pode-se perceber quão complexas e intrigantes são suas inter-relações de causa e efeito. A história geológica do Cenozoico permanece obscura tendo em vista as contradições e os conflitos apontados pela maioria dos autores, e que se individualizam nas obras de Ruddiman (1997) e Molnar et al. (1990). Para o primeiro, o soerguimento recente de terrenos montanhosos é a principal causa da mudança climática. Já para os segundos autores, o soerguimento é aparente, causado por compensações isostáticas, caracterizando assim o ciclo climático como desencadeador de mudanças no Sistema Terra. 


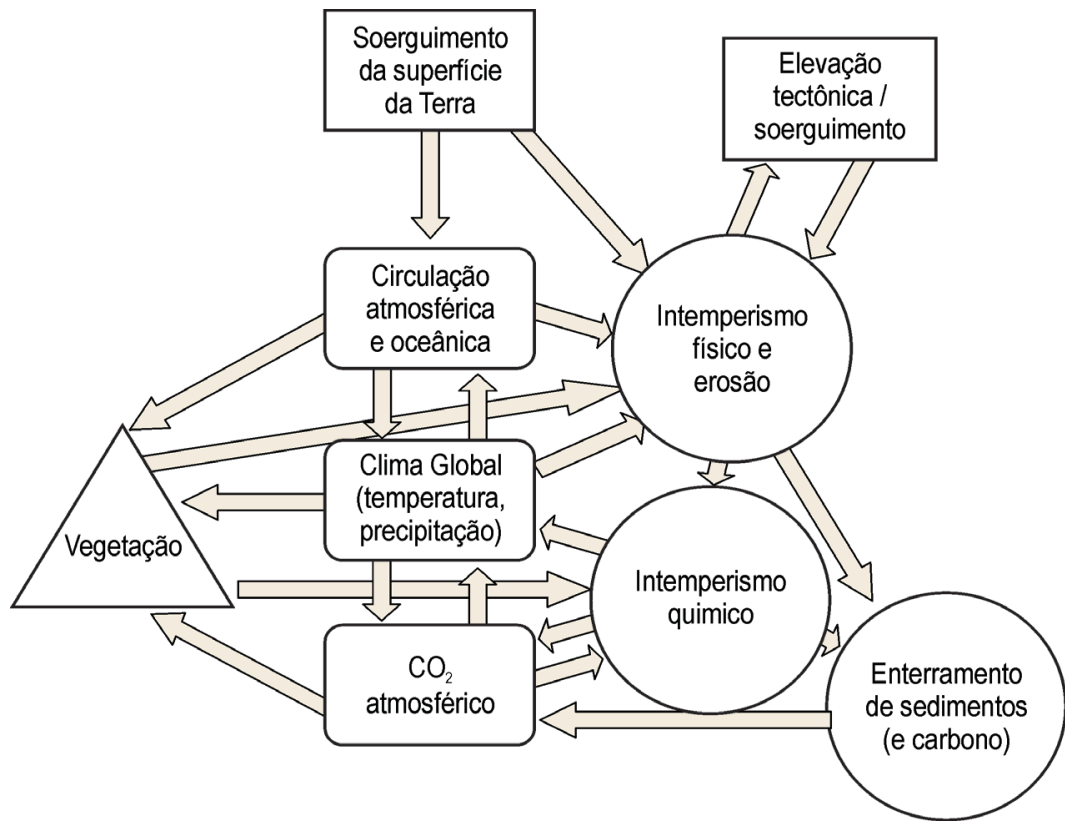

Figura 1. Principais fatores controladores da dinâmica do Sistema Terra relacionados à tectônica e clima. A ilustração esquematiza a interação entre eles, lembrando que as setas representam vetorialmente a interferência; por exemplo, o soerguimento tectônico da superfície terrestre altera os padrões de circulação atmosférica e oceânica, que por sua vez podem alterar ou ser alterados pelo Clima Global (Fig. modificada de Ruddiman 1997)

Um modo bastante sintético de se situar a polêmica entre as duas hipóteses existentes pode ser encontrado em Hay et al. (2002 p.746):

(1) a mudança climática é o resultado direto ou indireto do soerguimento tectônico, ou (2) a mudança climática não tem nada a ver com o soerguimento, mas tem alterado os processos superficiais da Terra, de tal forma a simular uma elevação generalizada.

A hipótese de número (1) corresponde à defendida por Ruddiman (1997) que considera que os efeitos da Tectônica no clima podem ser diretos ou indiretos, conforme apresentado na introdução deste trabalho. Já a de número (2), defendida por Molnar et.al.(1990) rejeita a hipótese de que as glaciações cenozoicas sejam efeitos do soerguimento recente em escala global, mas estas constituíram, antes de tudo, a causa da exumação de rochas, gerando uma aparente elevação da superfície terrestre, como explicitado por De Conto (2009, p.11):

O paradigma do soerguimento cenozoico causando resfriamento global e glaciação no hemisfério norte foi questionado por Molnar e England (1990), que argumentam que o aparecimento de elevação recente em diversas cadeias de montanhas distintas pode ser um artefato da mudança climática cenozoica e não a causa do resfriamento
A proposição, entretanto, não desqualifica ou invalida os processos interativos químicos e físicos descritos por Ruddiman (1997).

Apesar de ser consensual a existência de interferências entre os ciclos terrestres climático e tectônico, ainda há muitas incertezas quanto às suas relações e a importância dos papéis que desempenham, como afirmado por Hay et.al. (1996, p 433.):

É certo que tectônica e clima estão interrelacionados; contudo, relações específicas de causa e efeito e a importância relativa dos diferentes processos ainda permanecem pouco claros.

\section{Resultados obtidos}

\section{Bibliografia de referência}

Como exposto na metodologia, o fichamento dos textos deu origem a uma bibliografia de referência para a pesquisa no campo das interações entre Tectônica e Clima. Para facilitar a visualização da bibliografia utilizada foi produzido, para cada trabalho, um resumo simples do conteúdo do livro/ artigo e a explicitação da utilidade de cada texto para o presente trabalho, de acordo com o padrão: Referência e Titulo/resumo e utilidade. As referências completas encontram-se ao final do artigo. 
Buck W.R. 1991. Modes of continental lithospheric extension.

Apesar de sua contribuição para este trabalho não ser direta, este texto se mostrou indispensável na contraposição dos modelos principais e mais aceitos para o fenômeno de estiramento crustal.

Burke K. e Crowley T.J. 1998. Tectonic boundary conditions for climate reconstructions.

Este é um dos livros-base da pesquisa e contém exemplos e elucidação dos principais conceitos envolvidos.

Coward M.P. 1986. Heterogeneous stretching, simple shear and basin development.

Assim como o primeiro texto referido nessa listagem, este texto apresenta modelos de estiramento crustal. Foi mantido na bibliografia para garantir a análise criteriosa a respeito do fenômeno, já que ainda não existe consenso sobre como se dá a sua ocorrência.

De Conto R. M. 2009. Plate Tectonics and Climate Change. Encyclopedia of Paleoclimatology and Ancient Environments.

O autor apresenta os principais efeitos diretos e indiretos da tectônica no clima, padrões de circulação e confronta as duas principais hipóteses apresentadas na pesquisa.

Gradstein F.M., Ogg J.G., Smith A.G., Bleeker W., Lourens L.J. 2004. A New Geologic Time Scale, with special reference to Precambrian and Neogene.

Esta referência é fundamental, pois estabelece a Escala padrão do Tempo Geológico. A versão da escala internacional publicada em 2012 é a mais aprimorada e expandida da série (Gradstein et al. 2012), mas contínuas atualizações são divulgadas no sítio web da International Commission on Stratigraphy (http://www.kgs.ku.edu/General/Strat/internat. html), como a versão divulgada por Cohen et al. (2013).

Hay W.W. et al. 2002. The Late Cenozoic Uplift. Climate change paradox.

Este texto apresenta os dois principais paradigmas encontrados nesta pesquisa sendo, portanto, um dos mais relevantes.

Hay W.W. 1996. Tectonics and climate.

O texto apresenta a trajetória histórica das ideias que concernem à relação entre tectônica e clima e modelos de numéricos considerando parâmetros como pressão atmosférica e circulação oceânica.

Liccardo A. 2010. Tectônica de Placas; Influências no Clima.

Apresentação on-line que sintetiza o tema central da pesquisa e simplifica sua compreensão. Oferece subsídios para a criação de uma apresentação introdutória previamente à aplicação das atividades sugeridas neste trabalho.

Lister G.S., Etheridge M.A. e Symonds P.A. 1989.

Detachment models for the formation of passive continental margins.

Esse artigo é mais uma ferramenta na compreensão estrutural de modelos de formação de bacias por estiramento crustal e analisa, também, sua situação subsequente, a da formação de uma margem passiva.

Molnar P., England P. 1990. Late Cenozoic uplift of mountain ranges and global climate change: chicken or egg?

Este texto apresenta o contraponto teórico, revelando as contradições e modelos divergentes dentro do tema.

Ruddiman W.F. 1997. Tectonic Uplift and climate change.

Este é mais um livro-base da pesquisa. É extremamente completo no que diz respeito às teorias, principais conceitos e exemplos utilizados nesse trabalho.

Twiss R.J. \& Moores E.M. 1992. Structural Geology.

Livro base utilizado na análise estrutural dos processos tectônicos envolvidos na pesquisa e na compreensão dos artigos que tratam de casos específicos da movimentação crustal.

Unrug P. 1996. The assembly of Gondwanaland.

O artigo é uma referência central para a pesquisa porque reconstitui a história geotectônica do supercontinente Gondwana.

Watts 2001. Isostasy and Flexure of the Litosphere.

Livro utilizado na compreensão de processos geodinâmicos, como isostasia. Apresenta diversos modelos flexurais e é extremamente completo, trazendo exemplos sobre fenômenos isostáticos ao 
longo do tempo geológico.

Wernicke B. e Burchfiel B.C. 1982. Modes of extensional tectonics.

Este artigo interpreta fenômenos extensionais. Foi utilizado juntamente com os outros textos de análise de estiramento crustal na avaliação dos modelos propostos por diferentes autores.

\section{Desenvolvimento de atividade prática}

Durante a pesquisa foi desenvolvido um roteiro de atividade, a partir de modelos que vinham sendo pesquisados pelo extinto Departamento de Geociências Aplicadas ao Ensino (DGAE) e que prosseguem no Programa de Pós-Graduação em Ensino e História de Ciências da Terra (PEHCT) do Instituto de Geociências (IG-Unicamp). A atividade e os procedimentos envolvidos na sua execução são apresentados no item seguinte.

Já há algum tempo vinha sendo sentida necessidade de adequar a linguagem para a transmissão das informações dos conteúdos de Geociências para o ensino básico, que acaba sendo muito técnica para o público alvo" (Ferreira 2008)

A afirmação acima foi a base para a proposta do exercício, cujo foco é difundir o conhecimento geológico no ensino básico e incentivar práticas em Geociências, capazes de introduzir o estudante à metodologia científica a partir de experimentos prático-lúdicos. Devido à complexidade do tema e a necessidade do conhecimento prévio de alguns conceitos de Geociências, a atividade se destina a estudantes do ensino médio e prioriza o estímulo do raciocínio lógico aplicado ao Sistema Terra e o envolvimento do estudante, despertando assim sua curiosidade e facilitando o aprendizado. A intenção é que o experimento incentive os estudantes a dar continuidade ao processo de aprendizagem, pesquisando mais sobre o tema em outras fontes, e fixando o conteúdo teórico assimilado. Os conceitos apresentados devem ser traduzidos para uma linguagem mais simples pelo docente e utilizados como artefato na preparação dos estudantes para atividade, que requer uma introdução teórica.

O questionário e o debate sugeridos surgiram a partir da divergência dos modelos propostos por Ruddiman (1997) e Molnar et al. (1990), apresentados em Hay (1996) (ver desafios do tema). Considerando que os mecanismos que despertam as interferências entre clima e Tectônica e as mudanças em seus ciclos podem ser desencadeados tanto por um determinado fator quanto pelo outro, a justificativa para tal escolha reside no fato de que lidar com conflitos paradigmáticos é extremamente útil (Martins 2014) para despertar no estudante a percepção de que os processos terrestres são geralmente controlados por mais de um parâmetro, que isso é extremamente dinâmico e muitas vezes não existe um único modelo esclarecedor para o entendimento do que é observado.

\section{Atividade Prática}

Atividade Prática - Movimentos da superfície terrestre e dinâmica climática

Publico Alvo: Ensino básico

Questões prévias:

Quais são as possíveis variáveis terrestres que poderiam influenciar na dinâmica:

(a) tectônica?

(b) climática?

Conceitos envolvidos na atividade

\section{Experimento I}

A isostasia é o equilíbrio vertical da crosta terrestre sobre o substrato mantélico. O que controla esse fenômeno é a diferença de densidade ou peso dos dois componentes. Existem dois modelos explicativos independentes para o conceito de isostasia: o de Airy e o de Pratt, sendo que a maneira mais adequada de compreendê-lo resulta da integração de ambos, conhecida como modelo Pratt-Airy. A alteração topográfica resultante das diferenças de densidade é variável devido a mudanças da espessura dos pacotes litosféricos: quando há acúmulo de material, gera-se sobrepeso e, consequentemente, ocorre afundamento da região (subsidência), enquanto o alívio de peso provoca a emergência do terreno.

\section{Experimento II}

A criação de cadeias montanhosas (elevação da crosta) por movimentos tectônicos - soerguimento orogênico - ocorre, mais comumente, nos limites de placas convergentes (áreas de colisão e subdução). Em oposição ao soerguimento existe o movimento de subsidência da crosta - rebaixamento da superfície terrestre-comum em eventos tectônicos de distensão regional, falhamento e formação de grandes bacias. 
Feições topográficas de grande magnitude, como platôs e montanhas, por funcionarem como obstáculos, geram irregularidades na circulação atmosférica, modificando o padrão de circulação das partículas atmosféricas.

Longas cadeias montanhosas provocam um aumento da sinuosidade dos ventos na troposfera e constituem um dos fatores que controlam o albedo planetário; desse modo, influenciam o balanço energético global. Devido à influência sobre os processos erosivos e sobre fenômenos ligados a intemperismo físico e químico, as mudanças citadas interferem no ciclo da água na Terra e nos ciclos de diversos elementos químicos, como o carbono e nitrogênio, dentre outros.

\section{EXPERIMENTO I - ISOSTASIA}

Intuito da atividade: A atividade deverá permitir ao estudante visualizar como e por qual motivo ocorrem as compensações isostáticas e quais são seus efeitos na superfície terrestre.

Materiais necessários:

- Um recipiente rígido transparente (vidro ou acrílico) médio

- Copos transparentes de material rígido

- Bolinhas de gude ou de chumbo

- Água

- Pinça

Como fazer: Preencha até a metade o recipiente transparente com água. Em seguida coloque os copos no recipiente com água e as bolinhas nos copos até que estes tenham peso suficiente para que cada copo toque o fundo do recipiente (Fig. 2a). Para que o experimento seja bem sucedido não se deve deixar cair água dentro dos copos.

Após essa etapa, com a pinça, o estudante deverá remover com cuidado e aos poucos o número

(a)

(b)
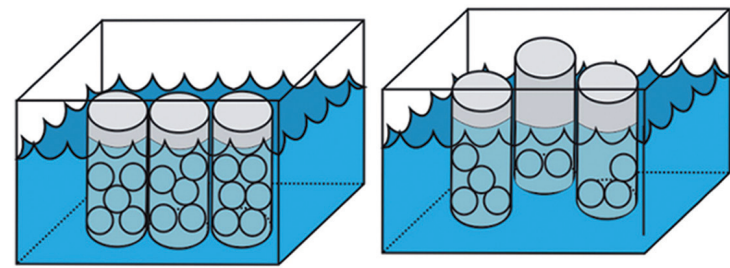

Figura 2. (Fig. 1 da atividade). Neste experimento a água representa o substrato mantélico e os copos, a crosta terrestre. (a) Notar que os copos devem tocar o fundo do recipiente. (b) A remoção das cargas deve gerar a elevação dos copos, representando um soerguimento isostático de bolinhas que achar pertinente de cada copo e observar o movimento e a mudança de posição dos copos conforme o peso é reduzido (Fig. 2b).

\section{Experimento II - Relevo e Atmosfera}

Intuito: Esta atividade deverá permitir ao estudante a visualização do comportamento das partículas atmosféricas através da constante reconfiguração topográfica terrestre.

Material Necessário:

- Caixa de papelão

- Papel picado

- Ventilador pequeno

Como fazer: Na primeira etapa do experimento o estudante deve fazer um recorte em um dos lados da caixa, onde colocará o ventilador pelo lado de fora da caixa. Após isso se colocam os papéis picados dentro da caixa, à frente do recorte feito, e aciona-se o ventilador. $\mathrm{Na}$ segunda etapa o aluno deverá fixar um anteparo no centro da caixa e de frente para o recorte feito para a passagem de ar. Este anteparo pode ser um pedaço de papelão com dimensões um pouco menores do que a caixa. Após isso se deve repetir a ação com os papéis e com o ventilador e observar como o anteparo interferiu no movimento dos papéis.

O professor deve propor aos estudantes um debate com os seguintes questionamentos:

Como a Tectônica pode influenciar o clima?

Como o clima pode influenciar a Tectônica?

Em que medida a geomorfologia interfere na dinâmica atmosférica? Cite exemplos.

Como o clima age na remoção das cargas?

Como a modificação do relevo - seja por fatores tectônicos elou climáticos - influencia a dinâmica atmosférica e no clima?

Como a alteração da dinâmica das correntes de ar pode alterar o clima local?

Podemos transportar esse modelo reduzido para escalas globais?

\section{Conclusões}

O desenvolvimento da pesquisa confirmou a decisiva influência dos fenômenos ligados à Tectônica de Placas na dinâmica climática da Terra, ao longo do Tempo Geológico. O principal interesse científico da Geologia, bem como uma de suas mais importantes contribuições ao conhecimento humano (van Loon 1999), decorre do fato de que a Terra é afetada, desde sua origem, por grandes 
mudanças ambientais (Hoffman 2009). São absolutamente constantes na história da Terra tanto a mudança climática, como as variações na disposição e morfologia de continentes e oceanos.

Longas cadeias montanhosas provocam aumento da sinuosidade dos ventos na troposfera; representam um fator que controla o albedo planetário e influencia o balanço energético global. Devido à interferência nos processos erosivos e em fenômenos ligados a intemperismo físico e químico, as mudanças citadas interferem no ciclo da água na Terra e nos ciclos de diversos elementos químicos, como o carbono e nitrogênio.

Foi possível reconhecer, por meio de levantamento bibliográfico, diferentes modelos teóricos para a relação entre Tectônica de Placas e o clima global. Alguns autores entendem que a Tectônica de Placas é responsável direta por alterações climáticas ao longo do Tempo Geológico, enquanto outros pesquisadores reconhecem tão somente a existência de uma intrigante ligação entre ambos os fatores. O grande desafio que o tema oferece reside precisamente em compreender quais são as variáveis atuantes e quão determinantes elas são.

\section{Referências}

Buck W.R. 1991. Mode of continental lithospheric extension.J. Geophys. Res., 96(12), 20p.

Burke K., Crowley T.J. 1998. Tectonic boundary conditions for climate reconstructions. Oxford Univ. Press.

Carneiro C.D.R., Brito-Neves B.B.de, Amaral I.A.do, Bistrichi C.A. 1994. O Atualismo como princípio metodológico em Tectônica. Bol. Geoc. Petrobrás. 8(2/4):275-293.

Cohen K.M., Finney S.C., Gibbard P.L., Fan J.-X. 2013. The ICS International Chronostratigraphic Chart. Episodes, 36(3):199-204. URL: www.episodes.org/index.php/epi/article/ view/59399/46434. Acesso 21.07.2015.

Constante A., Vasconcelos C. 2010. Actividades lúdico-práticas no ensino da geologia: complemento motivacional para a aprendizagem. Terre Didatica, 6(2):85-103. URL: http://www.ige.unicamp.br/ terraedidatica/. Acesso 21.03.2014.

Cooper M.A., Williams G.D. 1989. Inversion Tectonics. Geol. Soc. London, Special Publ. 44.

Coward M.P. 1986. Heterogeneous stretching, simple shear and basin development. Earth Planet. Sci. Letters, 80:325-336.

De Conto R.M. 2009. Plate Tectonics and Climate Change. Encyclopedia of Paleoclimatology and Ancient Environments. Springer. 1049 p.

Ferreira M.R.A. 2008. A construção de uma metodologia lúdica em Geociências: Reflexões sobre o Jogo da Memória e Oficinas pedagógicas como método de ensino de Minerais e Rochas nas escolas de Ensino Básico. URL http://www.geografiaememoria. ig.ufu.br/downloads/303_Marcus_Romero_Andrade_Ferreira_2008.pdf. Acesso 20.07.2012.

Gonçalves P.W., Carneiro C.D.R. 2008. La danza de los continentes en el tiempo geológico. Rev. de la Enseñanza de las Ciencias de la Tierra, 16(1):107116. URL: http://www.raco.cat/index.php/ECT/ article/view/120993/166508. Acesso 18.03.2010.

Gradstein F.M., Ogg J.G., Schmitz M.D., Ogg G.M. eds. 2012 The geologic time scale 2012. Amsterdam: Elsevier. 2v., 1.144p. URL: http://www.sciencedirect.com/science/book/9780444594259. Acesso 21.07.2015.

Gradstein F.M., Ogg J.G., Smith A.G., Bleeker W., Lourens L.J. 2004. A New Geologic Time Scale, with special reference to Precambrian and Neogene. Episodes, 27(3):83-100.

Hasui Y. 2012a. Evolução dos continentes. In: Hasui Y., Carneiro C.D.R., Almeida F.F.M.de, Bartorelli A. eds. 2012. Geologia do Brasil. São Paulo: Ed. Beca. p. 98-111. (ISBN 978-85-62768-10-1).

Hasui Y. 2012b. Tectônica de Placas. In: Hasui Y., Carneiro C.D.R., Almeida F.F.M.de, Bartorelli A. eds. 2012. Geologia do Brasil. São Paulo: Ed. Beca. p. 66-97. (ISBN 978-85-62768-10-1).

Hay W.W. 1996. Tectonics and climate. Geol. Rundsch., 85:409-437.

Hay W.W., DeConto R.M., Wold C.N. 1997. Climate: Is the past the key to the future?. Geol. Rundsch., 86(2):471-491.

Hay W.W. et al. 2002. The late cenozoic uplift. Climate change paradox. J. Earth Sci., 91:746-774.

Hoffman D.L. 2009. The Grand View: 4 Billion Years of Climate Change. Co2sceptic (Site Admin). ago 28th 2009. URL: http://climaterealists. $\mathrm{com} /$ ? id=3939. Acesso 20.07.2015.

Liccardo A. S.d. Clima e tectônica de placas. Ponta Grossa: Geoturismobrasil. URL: http://geoturismobrasil. com/aulasN.html. Acesso 6.10.2015.

Liccardo A. s.d. Tectônica de Placas. Influências no Clima. Ponta Grossa: Geoturismobrasil. URL: http://geoturismobrasil.com/aulasN.html. Acesso 6.10.2015.

Lister G.S., Etheridge M.A., Symonds P.A. 1989. Detachment models for the formation of passive continental margins. Tectonics, 10:1038-1064.

Martins J.R.S. 2014. Controvérsias e problematização no ensino de Geociências. Campinas: Inst. Geoc., Unicamp. (Tese Dout. PEHCT).

Molnar P., England P. 1990. Late Cenozoic uplift of mountain ranges and global climate change: chicken or egg? Nature, 346:29-34.

Ruddiman W.F. 1997. Tectonic Uplift and climate change. New York: Plenum Press. 
Toniolo J.C., Carneiro C.D.R. 2010. Processos geológicos de fixação do carbono na Terra e aquecimento global. Terra Didatica, 6(1):31-56. URL: http://www.ige.unicamp.br/terraedidatica/v6_1/ v6_1_A4.html. Acesso 2.08.2011.

Twiss R.J., Moores E.M. 1992. Structural Geology. W.H. Freeman \& Co. 532p

van Anden T.H. 1994. New views on an old planet. 2 ed. Cambridge: Cambridge Univ. Press. 439p. (reprinted 1995).

van Loon A.J. 1999. The meaning of "abrupteness" in the geological past. Earth Sci. Rev., 45:209-214.

Watts 2001. Isostasy and Flexure of the litosphere. Cambridge Univ. Press.

Wernicke B., Burchfiel B.C. 1982. Modes of extensional tectonics. J. Struct. Geol., 4(2):105-115.

RESUMO : Longas cadeias montanhosas exercem papel fundamental na dinâmica das esferas fluidas da Terra, pois 0 ar ascendente se resfria em zonas montanhosas e a umidade se condensa, causando precipitação orográfica e gerando aridez em zonas de sombra. Grandes áreas elevadas também aumentam a sinuosidade dos ventos na troposfera, participam do controle do albedo planetário e influenciam 0 balanço energético global. Esta síntese bibliográfica focaliza os efeitos na circulação atmosférica causados pela mudança dos limites das terras emersas e do relevo, em escala continental. Processos endógenos interferem nos padrões de denudação e nos ciclos da água e de elementos químicos como carbono e nitrogênio. Não há consenso, entretanto, no entendimento dessa dinâmica: vários pesquisadores atribuem papel decisivo da Tectônica de Placas nas alterações climáticas globais ao longo do Tempo Geológico, enquanto outros identificam apenas uma singela, porém intrigante, ligação. Apresenta-se proposta de atividade didática para visualização das interações entre o relevo e a atmosfera.

PALAVRAS-CHAVE: Geologia, circulação atmosférica, oceanos, orogênese, ensino-aprendizagem. 